\title{
Postconflicto y justicia transicional en Colombia: balance de nuestra experiencia*
}

\author{
Carolina Rodríguez Rodríguez
}

\begin{abstract}
Resumen
Recibido: 17 de noviembre de 2010 Revisado: 14 de diciembre de 2010 Aprobado: 10 de febrero de 2011

El estudio establece la relación entre el postconflicto y la justicia transicional, integrando las conceptualizaciones realizadas por los especialistas nacionales e internacionales y los datos históricos y empíricos aportados desde las sociedades en transición. El propósito es analizar el caso colombiano a partir de estos referentes, para esclarecer si el país vive una situación postconflicto y cuál es el balance de la aplicación de las estrategias de la justicia transicional consagradas en la Ley de Justicia y Paz (Ley 975 de 2005). De esta manera, la investigación articula elementos teóricos y fácticos, con la finalidad de generar recomendaciones normativas para la implementación futura de estrategias transicionales, teniendo como criterio regulativo el equilibrio entre la política y el derecho y, sobre todo, un papel activo de las víctimas y de la sociedad civil.
\end{abstract}

\section{Palabras clave}

Postconflicto, justicia transicional, verdad, justicia, reparación y reconciliación.

* Este artículo constituye un resultado de investigación inscrito al grupo interinstitucional Filosofía, realidad y lenguaje (A1), adscrito a la Facultad de Filosofía y Humanidades de la Universidad de La Salle y a la Maestría en Filosofía Latinoamericana de la Universidad Santo Tomás. El artículo hace parte del proyecto Escenarios para una sociedad colombiana postconflicto. Propuesta desde una perspectiva de paz y DD.HH., financiado por el Centro de Investigación en Hábitat, Desarrollo y Paz (CIHDEP) de la Universidad de La Salle.

** Licenciada en Filosofía y Letras, especialista en Educación y magíster en Filosofía Latinoamericana de la Universidad Santo Tomás. Candidata a doctora en Filosofía en la Pontificia Universidad Javeriana. Docente de la Facultad de Filosofía y Humanidades de la Universidad de La Salle y de la Maestría en Filosofía Latinoamericana de la Universidad Santo Tomás. Líder de los grupos de investigación Filosofía, realidad y lenguaje (A1) y Estudios hobbesianos (C). Correo electrónico: crodriguez@unisalle.edu.co 


\title{
Post-conflict and Transitional Justice in Colombia: Results of our Experience
}

\author{
Carolina Rodríguez Rodríguez
}

\begin{abstract}
This study seeks to establish the existing relationship between post-conflict and transitional justice, integrating both the conceptualization of national and international specialists and the historical and empirical data from societies in transition. The purpose is to analyze the Colombian case using these references as starting points, in order to establish whether the country is in a post-conflict situation and to establish the current result of the application of transitional justice strategies encoded in the "Ley de Justicia y Paz" (Ley 975 de 2005). In this way, the research integrates theoretical and factual elements, in order to produce normative recommendations for the future implementation of transitional strategies, using the equilibrium between politics and law as a regulating criterion and, specially, giving a more active role to victims and civil society.
\end{abstract}

\section{KEYWORDS}

Post-conflict, transitional justice, truth, justice, compensation, reconciliation.

Recibido: 17 de noviembre de 2010 Revisado: 14 de diciembre de 2010 Aprobado: 10 de febrero de 2011 


\section{Planteamiento del problema}

La investigación tiene como objetivo elucidar las relaciones entre el postconflicto y la justicia transicional para establecer si Colombia es una sociedad postconflicto y si se encuentra en un proceso real de transición. Para lograr este objetivo es necesario comprender las relaciones de causalidad entre los fenómenos a estudiar. Se precisa indagar si la aplicación de las medidas de justicia transicional en medio del conflicto armado puede llegar a producir un escenario postconflicto en el futuro, o, por el contrario, si la situación postconflicto debería ser la exigencia mínima para una incorporación coherente y efectiva de la justicia transicional.

En torno a la categoría "postconflicto" no existe un consenso mínimo. Más aún, en las investigaciones académicas parecería omitirse intencionalmente, lo que contrasta con las intervenciones de los funcionarios del gobierno y de los representantes de la clase política, en donde el término tiende a ser aceptado como si designara hechos evidentes ${ }^{1}$. Si bien en la literatura internacional se admite el postconflicto como uno de los tipos de transición, en Colombia el debate tiende a problematizar la versión de justicia transicional incorporada a la Ley de Justicia y Paz, eliminando la categoría "postconflicto" de los análisis.

De hecho, especialistas en el tema como Uprimny y Saffon han acuñado la expresión justicia transicional sin transición ${ }^{2}$, desde la

1 Este es el caso José Obdulio Gaviria, Humberto de la Calle Lombana, Augusto Ramírez Ocampo y Eduardo Pizarro Leongómez, entre otros.

2 Esta expresión se refiere a la implementación del marco legal de la justicia transicional en un contexto en donde no ha tenido lugar la transición de la guerra a la paz, del autoritarismo a la democracia o de un régimen de exclusión racial a uno de inclusión multicultural. cual formulan el siguiente cuestionamiento: “¿Conviene usar o no el lenguaje y los enfoques de la justicia transicional en un contexto como Colombia, en donde no es claro que esté ocurriendo una verdadera transición de la guerra a la paz?" (2009, p. 162). En el mismo sentido, Camila de Gamboa Tapias califica el caso colombiano como una transición fallida (2006). La desmovilización parcial de algunos de los grupos involucrados en el conflicto armado no permite la aplicación rigurosa de la justicia transicional, ni menos la declaración de un postconflicto.

Por esta razón, a propósito de las categorías de análisis, esta investigación busca establecer cuál es la relación normativa entre la política y la ley en la construcción de marcos legales para la transición, a la luz de la siguiente pregunta: desde el punto de vista normativo, ¿cuáles deberían ser las relaciones entre una situación postconflicto y las medidas de justicia transicional?

\section{Estado del ARTE}

En el 2005 Colciencias auspició el estudio Estado de la investigación sobre conflicto, postconflicto, reconciliación y el papel de la sociedad civil en Colombia, realizado por María del Rosario Guerra y Juan José Plata. De este texto se destaca el balance retrospectivo frente al conflicto armado en Colombia. No obstante, su principal limitación fue no profundizar en el debate sobre el postconflicto y deja por fuera las principales reacciones académicas frente al tema de la justicia transicional.

Otro antecedente de la presente investigación son los estudios coordinados por Angélica Rettberg y publicados por la Universidad de los Andes. En el 2002 apareció el texto Preparar el futuro: conflicto y 
postconflicto en Colombia. Si bien este trabajo reconoce que Colombia no se encuentra en una situación de postconflicto, establece una importante conclusión derivada de las experiencias internacionales: los escenarios postconflicto deben empezarse a construir en medio del conflicto, porque es la única forma de garantizar una futura paz sustentable.

En el debate suscitado por la Ley de Justicia y Paz, la profesora Rettberg coordinó la publicación del libro colectivo Entre el perdón y el paredón. Preguntas y dilemas de la justicia transicional (2005). En esta obra participaron reconocidos especialistas como Colling Duggan, Leonardo Fillipini, Lisa Magarell, Carsten Stahn y Mark J. Osiel, entre otros. El objetivo de la obra fue posicionar el tema de la justicia transicional en la discusión pública, para analizar la adecuación de la Ley de Justicia y Paz con los marcos teóricos especializados y a las experiencias internacionales más significativas en el campo de la verdad, la justicia y la reparación. También resultó muy importante el análisis desde la perspectiva del derecho internacional, teniendo en cuenta el cumplimiento de los estándares mínimos de la justicia transicional.

En este estado del arte ocupan un lugar central las investigaciones realizadas por Rodrigo Uprimny, quien aporta una extensa producción al tema de estudio. Por las limitaciones de espacio, mencionamos sólo cuatro de ellas: Verdad, reparación y justicia para Colombia (2004), Justicia transicional y justicia restaurativa. Tensiones y complementariedades (2005), iJusticia transicional sin transición? Verdad, justicia y reparación para Colombia (2006) y Usos y abusos de la justicia transicional en Colombia (2009).
El hilo conductor de estos trabajos es el siguiente: ofrecer herramientas conceptuales, normativas y empíricas para reflexionar sobre los equilibrios y complementariedades entre la justicia transicional y la justicia restaurativa. Estos estudios reconocen la necesidad de ajustar el proceso colombiano a los estándares internacionales y a los imperativos de la nueva conciencia humanitaria. En lo fundamental, Uprimny y sus coinvestigadores identifican en la interpretación local de la justicia transicional dos intencionalidades completamente diferentes: 1) Un uso manipulador, cuyo objetivo es perpetuar ciertas formas de statu quo y promover la impunidad; se trata sólo de un instrumento retórico y opresivo que no produce transformaciones reales en el diseño institucional. 2) Un uso democrático y emancipatorio, centrado en la denuncia de la impunidad y en la restauración de los derechos de las víctimas, los cuales han sido violados sistemáticamente. Se recomienda hacer un uso cauteloso y prudente de la justicia transicional, evitando disolverla o simplificarla en un enfoque restaurativo, desde una perspectiva interesada y pragmática.

La realización del presente estado del arte permite concluir: 1) La necesidad de preparar los escenarios postconflicto en medio del conflicto, para llegar a consensos entre la sociedad civil, acerca de los contenidos básicos de un nuevo pacto social. 2) El diseño de futuros escenarios postconflicto no tiene un porqué negar la persistencia del conflicto armado interno ni propiciar una apropiación anómala o descontextualizada de las estrategias de la justicia transicional; en efecto, en Colombia se aplican sin que se haya dado una verdadera transición hacia una situación postconflicto y 3) el debate académico 
sobre la justicia transicional liderado por las investigaciones universitarias y por las $\mathrm{ONG}$ constituye un factor de presión para orientar una aplicación más transparente, abierta y participativa de la Ley de Justicia y Paz.

\section{Diseño metodológico}

Esta investigación asume una reconstrucción teórica de las experiencias internacionales más significativas desarrolladas por las sociedades transicionales. Si bien las conclusiones de esta reconstrucción, por razones de espacio no se presentan en su totalidad en este breve informe, fueron fundamentales para comprender cuáles son los mínimos estándares que se deben incorporar a un proceso transicional, así como para realizar el balance de los casos exitosos y de las experiencias fallidas. De esta manera, el referente internacional aportó información tanto teórica como empírica para contrastar el caso colombiano, sustentado en la construcción e implementación de la Ley de Justicia y Paz. A partir de este balance realizado desde una perspectiva descriptiva, el estudio culmina con la formulación de recomendaciones o mínimos normativos para la justicia transicional, como criterios para la orientación de la acción práctica y la toma de decisiones.

\section{Resultados}

\section{Génesis e implementación de} la Ley de Justicia y Paz

La Ley 975 de 2005 fue una iniciativa legislativa posterior al proceso unilateral de desmovilización de los paramilitares, lo que ha generado la sospecha de una eventual presión de estos grupos para la legitimación de los hechos cumplidos y la legalización de la organización ${ }^{3}$. Las AUC se desmovilizaron primero y luego se creó el marco legal para su procesamiento penal y reinserción. Así, con el reconocimiento del carácter político de estos grupos inició la aplicación de la justicia transicional en Colombia.

Ahora bien, el énfasis en la desmovilización y judicialización, evidencian una ley centrada desde su génesis en los perpetradores y no en las víctimas, porque su objetivo inicial no fue la reparación sino la aplicación de penas alternativas para los delitos de lesa humanidad ${ }^{4}$. Sectores sociales como las ONG y las asociaciones de víctimas han formulado fuertes cuestionamientos a la legitimidad de la ley, pues identifican que en los paramilitares se constituyó un grupo de presión que exigió la redacción de esta ley en unos términos favorables para ellos.

Además, la ley fue sancionada por un Congreso cuya mayor parte de sus miembros, posteriormente, fue investigada y/o procesada por nexos con las AUC. La base empírica para estas afirmaciones fueron las versiones libres rendidas por los mismos paramilitares desmovilizados y los estudios realizados por Claudia López y León Valencia, entre otros investigadores (2007). Estos estudios mostraron la correlación existente entre los grupos paramilitares en ciertas regiones del país, como la costa Atlántica, y la configuración de un nuevo mapa electoral que benefició a la coalición de gobierno.

Las ONG, los representantes de la academia y las asociaciones de víctimas también imputaron la validez de la Ley de Justicia y Paz a

3 En este sentido convergen los trabajos de López (2007), Valencia (2009) y Uprimny (2009), entre otros.

4 Este hecho ya se anunciaba en la versión su versión anterior (el proyecto de Ley de Alternatividad Penal). 
partir de hechos como la presencia de los jefes paramilitares en el Congreso de la República, las visitas secretas de algunos de ellos a la Casa de Nariño y el reconocimiento del carácter político de las AUC como un actor de contrainsurgencia en el conflicto armado.

La Ley de Justicia y Paz no sólo ha sido cuestionada por su génesis y por los móviles de impunidad subyacentes. También ha sido objeto de amplia crítica por las condiciones anormales de su implementación, que ratifica en el discurso y no en los hechos, el advenimiento de una etapa postconflicto. De una manera sistemática, el discurso gubernamental ha intentado negar la existencia de un conflicto armado interno. Este hecho ha tenido en la opinión pública un efecto confuso, al oscilar entre la identificación de una amenaza terrorista -con la pretensión de usurpar al Estado el monopolio legítimo de la fuerza-, y la adopción de un imaginario colectivo en torno a una creciente situación postconflicto.

En medio de la polarización extrema, promovida por el discurso gubernamental, es muy difícil pensar en la reconciliación social, en tanto principal objetivo de la justicia transicional. Además, la negación del conflicto armado no lo resuelve; más bien exacerba sus causas e impactos. Estas circunstancias hacen poco viable la incorporación real del paradigma de la justicia transicional, porque en medio del conflicto armado no es posible garantizar la no repetición de las atrocidades.

Ni las víctimas, ni la sociedad civil tuvieron una participación, aunque fuera discreta, en el diseño de la Ley de Justicia y Paz. Las experiencias internacionales, y especialmente el caso de Sudáfrica, ilustran que el éxito de las estrategias transicionales son directamente proporcional a la participación e inclusión de amplios sectores de la sociedad. Aunque la Ley de Justicia y Paz habla de las víctimas, las excluyó desde el inicio del proceso. Entonces, ¿cómo se van a reconciliar los sujetos ausentes en la transición?

En Colombia algunos sectores con dominio político e influencia social parecen entender y aplicar los principios fundamentales sobre los cuales se sustenta la justicia transicional lo que ha conducido una versión bastante libre y eminentemente pragmática, por decir lo menos, de este paradigma, versiones que pueden conducir a desvirtuarlo y a anular las grandes posibilidades que ofrece la justicia transicional para evitar la no repetición y para fortalecer la democracia (Uribe de Hincapié, 2007, p. 29).

\section{SOBRE EL CUMPLIMIENTO DE LOS OBJETIVOS DE LA JUSTICIA TRANSICIONAL}

\section{Los límites de la verdad}

El tema de la verdad evidencia importantes falencias tanto en la concepción de la Ley de Justicia y Paz y en su implementación. Como resulta lógico, en medio del conflicto no es posible crear comisiones de verdad. Las experiencias internacionales demuestran la importancia del cese al fuego y el desarrollo de los primeros acuerdos de paz para la conformación de estas comisiones. Por supuesto, ese no es el caso colombiano.

Por otra parte, la Ley de Justicia y Paz hace énfasis más en la judicialización de los perpetradores y en el establecimiento de penas alternativas, y la reconstrucción de la verdad histórica y la recuperación de la memoria. Esto convierte a la verdad en un objeto intercambiable, entregado para obtener 
beneficios jurídicos; la verdad es la moneda para transar y negociar, según los vaivenes de las negociaciones políticas (Uribe de Hincapié, 2007). Es así como adquiere fuerza la verdad procesal, relegando a un segundo plano la comprensión exhaustiva de las causas que originan, mantienen y perpetúan el conflicto. Sin embargo, sólo la apropiación consciente y reflexiva del pasado violento, puede dar las lecciones suficientes para diseñar garantías de no repetición.

La verdad, así pensada, tiene una dimensión colectiva, social, podríamos decir que apunta a señalar la importancia que para cada pueblo tiene el conocimiento de su historia de opresión y de maltrato, las circunstancias y los motivos que llevaron a semejante desastre humanitario y las responsabilidades del Estado y de los distintos operadores de violencia en la perpetración de crímenes de guerra y de lesa humanidad. La historia y la memoria constituyen un patrimonio inalienable de los pueblos y estos tienen la obligación de recordar y de luchar contra el olvido (Uribe de Hincapié, 2007, p. 30).

Aunque en Colombia se enfatiza en la verdad judicial, los avances en este campo han sido precarios y ello dificulta el restablecimiento del derecho de las víctimas a conocer qué sucedió, porque en las versiones libres los perpetradores entregan una verdad incompleta y fragmentaria ${ }^{5}$. Las verdades parciales no llevan a una reconstrucción de

5 En las versiones libres los perpetradores cuentan lo que quieren y no existe una penalización significativa para la omisión de información (sólo un incremento del 20\% de la pena, que inicialmente es entre 5 y 8 años). Por otra parte, según las víctimas, la extradición de 14 jefes paramilitares a Estados Unidos vulnera su derecho a la verdad, porque los perpetradores extraditados quedan por fuera de la Ley de Justicia y Paz; aunque las penas impuestas por la justicia norteamericana pueden ser más duras, la posibilidad de reconstruir los hechos a partir de sus versiones se extingue. Además, no deja de ser significativo que en Estados Unidos serán procesados por narcotráfico y no por delitos de lesa humanidad. la memoria histórica ni a propiciar procesos de reconciliación, porque estas "verdades rivales, parciales y restringidas funcionarán como ejes reproductores de los conflictos, como prolongación de las venganzas, como justificaciones morales y políticas para continuar o reemprender la guerra" (Uribe de Hincapié, 2007, p. 31).

En nuestro país la reconstrucción de la memoria recae en los victimarios y no en la memoria de las víctimas, impidiendo la catarsis para el dolor individual y social. Esto no genera espacios públicos para que los perpetradores puedan asumir sus culpas y finalmente, inhibe la reconciliación de todos los sectores de la sociedad 6 . Sin embargo, desde la perspectiva de la CNRR, resultaría "viable afrontar la verdad y la justicia, sin generar tensiones traumáticas que simple y llanamente sólo sirvan para prolongar el sufrimiento de los colombianos" (Pizarro, 2009, p. 13).

En contraste, las experiencias transicionales internacionales insisten en la necesidad de conocer el pasado y de no incurrir en perdones amnésicos en nombre de la reconciliación. En este mismo sentido y a propósito del genocidio acaecido con la Segunda Guerra Mundial, se pronunció el filósofo Theodor Adorno, para que Auscwitz no se repita ${ }^{7}$; también se inscribe la experiencia de la transición guatemalteca, en donde la verdad subjetiva de las víctimas jugó un papel preponderante, más allá de la verdad objetiva de las investigaciones judiciales. Esta experiencia propendió por una justicia transicional construida desde abajo. Según Mersky,

6 A este respecto, las comisiones de verdad sudafricanas constituyen un referente mundial.

7 Adorno emitió esta proclama en la conferencia, La educación después de Auschwitz, transmitida por Radio Hesse, el 18 de abril de 1966. 
El punto de partida del trabajo fue las versiones de las víctimas. Éstas se complementaban y contrastaban, obviamente, con otras múltiples fuentes, que casi siempre confluían en el mismo sentido de los testimonios y que permitían construir el marco interpretativo. La labor investigativa de la $\mathrm{CEH}$, que combinaba el trabajo con los testimonios de las víctimas, con el análisis histórico y jurídico, llevó a la formulación de conclusiones que reconocieron la veracidad de las palabras de las víctimas; y les dieron credibilidad y legitimidad luego de años de invisibilización, negación y criminalización. De esta manera se convirtió en una primera medida importante de reparación (Mersky, 2007, pp. 5-6).

Sólo el reconocimiento del papel central de las víctimas en la transición permite la construcción de un nuevo pacto social (Lefranc, 2007, p. 14) ${ }^{8}$. Por ello, urge la reconstrucción comprensiva del proceso histórico asociado al conflicto, como un relato colectivo que intente ponderar la influencia del pasado en la configuración del presente y en el diseño de posibles escenarios futuros ${ }^{9}$.

\section{Dilemas en la justicia}

El alcance de la justicia en la Ley 975 de 2005 ha sido restringido y no ha estado exento de dilemas. Ya el proyecto de Ley de Alternatividad Penal evocaba las leyes de perdón y olvido aplicadas en los países del Cono Sur,

8 Explica que la reconstrucción de la perspectiva de las víctimas generalmente ha estado asociada a su sufrimiento físico y moral, pero no a su militancia política; las comisiones de verdad tienden a reconstruir sus historias privadas, pero no el significado que estas tiene en la trama de la vida pública.

9 Por supuesto, también es posible encontrar voces de disenso, que critican la exagerada primacía de la memoria sobre el olvido. Tal es el caso de Orozco (2005), quien se distancia de una sacralización de la memoria, porque la considera una expresión de la justicia de los vencedores y del recordatorio permanente de la tragedia y el holocausto. Esto, a fin de cuentas, podría fustigar una actitud vengativa y justiciera que imposibilite la reconciliación. durante las transiciones de la dictadura a la democracia; esta ley propugnaba por indultos y amnistías generalizadas como una forma de pasar la página y de promover la reconciliación. Por supuesto, las reacciones y críticas no se hicieron esperar y ante la posición enérgica de la comunidad internacional, los colectivos de abogados, los académicos, las ONG y las asociaciones de víctimas, se reformuló el proyecto hasta dar forma a la actual Ley de Justicia y Paz.

Aún con las reformas no todos los sectores quedaron satisfechos y las objeciones persistieron. Especialmente, en lo concerniente a la proporcionalidad entre penas y delitos cometidos, más cuando estaban en juego delitos de lesa humanidad, catalogados como imprescriptibles y no sujetos a amnistía por parte de ninguna legislación interna. El principal tema de debate ha sido el establecimiento de penas entre cinco y ocho años para castigar genocidios y delitos de lesa humanidad. Esto con el siguiente agravante: la posibilidad de descontar el tiempo de concentración en Santafé de Ralito a la máxima pena impuesta. Así, para los observadores nacionales e internacionales las penas resultaron irrisorias y sin una verdadera capacidad retributiva ${ }^{10}$. Por ello plantean que los ideales de la paz y la reconciliación, así como los intereses y motivaciones de la política no pueden superponerse al ámbito jurídico. Sólo una posición conservadora como la asumida por Schmitt estaría dispuesta a sacrificar los derechos

10 Según Arango: "Desde la perspectiva iusfilosófica la decisión de no sancionar proporcionadamente el delito de lesa humanidad es equivocada. Esto ofende las emociones morales de las víctimas y hace indeseable e ilegítima la práctica jurídica del país, diluye el derecho en la política y desconoce los derechos humanos. Resultaría intolerable y denigrante para la población del país verse representada por criminales de lesa humanidad por el simple hecho de que con sus mal habidas fortunas pueden comprar las conciencias suficientes para hacerse elegir" (2007, p. 57). 
individuales en función del bien común y al individuo en aras de la colectividad.

Más allá del debate entre dos extremos tan inconmensurables como el conservadurismo y el rigorismo penal, resulta necesario ponderar si unas penas más severas pondrían en cuestión la viabilidad de esta transición anormal, pues qué grupo al margen de la ley estaría dispuesto a desmovilizarse para asumir todo el peso de la justicia retributiva; más cuando al inicio de la desmovilización los paramilitares anunciaron su negativa a pagar un solo día de cárcel. Si bien en un proceso transicional normal los perpetradores no suelen ser procesados con las penas de la justicia ordinaria y que para tal efecto se crea un marco jurídico alternativo, de todos modos sí debe existir una dosis de castigo.

Frente a esta conclusión surge un nuevo debate: si en el caso de las AUC -el único grupo desmovilizado-, la discrecionalidad presidencial puede determinar quiénes pueden ser candidatos para acogerse a la Ley de Justicia y Paz. También aparecen cuestionamientos sobre las capacidades del sistema judicial para procesar a todos los movilizados. Frente a esto Pizarro Leóngomez defiende la posibilidad que sólo los altos jefes paramilitares sean juzgados. Su propuesta no es adelantar juicios masivos sino ejemplarizantes. Para no generar una parálisis judicial, sugiere la implementación de un modelo similar al aplicado en la antigua Yugoslavia (Pizarro, 2009, p. 87). Esta solución también ha recibido cuestionamientos enérgicos. Para algunos analistas la Ley de Justicia y Paz -dados los tiempos, mecanismos y restricciones estipulados- parece estar diseñada para promover la impunidad al excluir a una parte significativa de los desmovilizados del procesamiento legal.

Otro debate significativo se ha dado en torno a la posibilidad de sustituir la justicia transicional con un esquema de justicia restaurativa, centrado en amplias reparaciones para las víctimas y en la atenuación de las penas para los victimarios. Autores como Uprimny (2009) y Uribe de Hincapié (2007) han señalado los límites de este enfoque, porque podría convertirse en un argumento oportunista que abre paso a la impunidad, y además no asegura una reparación efectiva para los derechos vulnerados de las víctimas. Según lo denuncian estos autores, detrás de todo este fenómeno se esconde el objetivo de minimizar el alcance punitivo del castigo.

De todos modos el balance del tema de la justicia en la transición colombiana arroja un saldo en rojo. Aún siendo flexibles con la aplicación del paradigma, es posible establecer que en el país no se ha dado ni retribución (justicia punitiva) ni reparación (justicia restaurativa). Además, si siguiéramos la indicación de Lefranc (2007), de evaluar el componente de la justicia en las transiciones a la luz del impacto en las reformas institucionales y en los procesos de democratización, el balance sigue siendo precario.

En el marco del debate en torno a la proporcionalidad de las penas y al alcance de la retribución o punición, Pizarro Leongómez propone mediar entre el minimalismo pragmático y el maximalismo moral. Esta solución aboga por un equilibrio entre el minimalismo inicialmente propuesto por la Ley de Alternatividad Penal y el maximalismo reclamado por las víctimas. Aún así, en la aplicación de la Ley de Justicia y Paz no pueden desconocerse el marco jurídico 
internacional ni la nueva conciencia humanitaria, porque los Estados no pueden promover la impunidad ni la trivialización de las penas, incorporando discrecionalmente los mandatos del derecho internacional.

\section{REPARACIONES INCIPIENTES}

La reparación y restauración también se encuentran en un estado precario. No hay un reconocimiento de las víctimas, ni en el sentido estadístico ni en el social. En primer lugar, no se cuenta con un consolidado departamental ni nacional, que permita establecer quiénes son las víctimas, cuántas son o donde están, ni cuales fueron los modos $o$ agentes de la victimización. En segunda instancia, no se ha dado un proceso de reconocimiento social debido a la ausencia de estrategias verdaderamente inclusivas, diseñadas por el Estado o por la sociedad civil.

La Ley de Justicia y Paz no hace tanto énfasis en la reparación de las víctimas como en la reinserción de los desmovilizados. Sobre todo, esta ley no fue concebida a la luz de los principios de Joinet, en donde se consagran los mínimos estándares internacionales a tener en cuenta en las reparaciones. En este contexto sorprende la siguiente afirmación de Pizarro: "la Ley de Justicia y Paz tuvo una virtud inesperada: permitió la visibilización de las víctimas como portadoras de derechos" (2009, p. 51). Ante esta declaración es necesario preguntar ¿cuáles eran los resultados esperados y para qué fue formulada la ley?

De hecho, el hundimiento de la Ley de Víctimas puso en evidencia la falta de voluntad política del Estado para asumir la responsabilidad de la reparación, con el siguiente argumento: si el Estado no es el perpetrador, de participar en las reparaciones lo haría por solidaridad y no por responsabilidad. No obstante, se estimó la reparación como una carga dispendiosa para el país, porque los recursos demandados por un proceso sistemático y efectivo constituyen un peso fiscal que excede las capacidades financieras del Estado. Entonces, la responsabilidad de la reparación corresponde a los grupos ilegales, en este caso de los paramilitares desmovilizados, quienes responderán con los bienes ilícitos, pero no con su patrimonio habido legalmente. Además, la Ley de Justicia y Paz estableció que las responsabilidades por la reparación de las víctimas es individual y no de las AUC como organización. Por supuesto, este modo de enfocar el asunto contradice las experiencias acumuladas internacionalmente, porque las reparaciones insuficientes no contribuyen a la verdadera reconstrucción social de un país en transición.

Todo lo anterior muestra la precariedad de las acciones, tanto en el reconocimiento y dignificación de las víctimas como en las reparaciones materiales y simbólicas. En el plano de la reparación administrativa las cifras fijadas para la compensación resultan irrisorias y no contribuyen al restablecimiento del proyecto de vida de los afectados por la violencia, ni al fortalecimiento de la reconstrucción temprana o de la atención humanitaria oportuna. En muchos casos, el sólo hecho de intentar acreditar la condición de víctima puede constituirse en una nueva forma de victimización.

$\mathrm{Ni}$ el reconocimiento de las necesidades de las víctimas ni la reparación de los daños sufridos han sido una agenda prioritaria en un proceso transicional tan anormal como el colombiano, en donde ellas han sido 
ignoradas, estigmatizadas y excluidas ${ }^{11}$. No obstante, el daño infligido victimiza a la sociedad en su conjunto, porque las pérdidas, los daños y las violaciones no sólo recaen en los individuos sino en la colectividad.

En este sentido, faltan estrategias para lograr mayores acercamientos entre las víctimas y la sociedad civil conducentes a establecer los contenidos mínimos del nuevo pacto social, que en último término es el objetivo de la transición. Por esta razón, la dignificación de las víctimas debería convertirse en una construcción social y política, orientada a su humanización y a fomentar actitudes sociales como la indignación y el repudio ante las atrocidades cometidas.

Una sociedad cuyo objetivo es vivir una transición social y política real, debe recuperar la sensibilidad, para no observar con normalidad las atrocidades. En este contexto resulta muy oportuna la propuesta de Rodolfo Arango, quien reconoce en las emociones morales un factor crucial en las interacciones sociales durante la transición. Emociones como la vergüenza, la indignación, la culpa, la ira, el resentimiento y la compasión deben aflorar en un proceso de catarsis nacional para emprender un camino posible hacia la reconciliación (2007, pp. $66-80)^{12}$. Por ello, la recuperación de la memoria colectiva frente a las atrocidades, entendiendo qué lugar ocupan en ella las emociones morales que las víctimas se conviertan en sujetos negados e invisibles. Según Iván Cepeda,

11 Los procesos de atención hacen mayor énfasis en el impacto del desplazamiento forzado, pero aún no se intervienen consistentemente otras formas de victimización.

12 Sin embargo, la emoción predominante es el miedo. En muchos casos esto impide que las víctimas asuman su identidad en cuanto tal, por miedo a la retaliación de los perpetradores o a la estigmatización de la sociedad. ...un aspecto insoslayable de la apertura a ese disenso democrático y democratizador pasa necesariamente entonces por preguntar cuál es la situación de las víctimas antes de la transición y los acuerdos de paz: ¿Qué posición ocupan ellas en la sociedad? ¿Han logrado ganar una identidad colectiva $\mathrm{o}$ permanecen anónimas? ¿Han accedido al espacio público o están relegadas al ostracismo? ¿Cuáles son los peligros que aún se ciernen sobre ellas, y en especial sobre las comunidades en riesgo de extinción? ¿Cuáles han sido los rasgos de las modalidades de victimización que han determinado su situación actual? ¿En qué medida el daño sufrido por una comunidad dada ha afectado al conjunto de la sociedad? ¿Qué procedimientos y medidas se requerirán para que esos grupos forzados a la marginalidad participen en la controversia pública sobre los crímenes del pasado? (Cepeda, 2005, p. 261).

\section{LOS RETOS DE LA RECONCILIACIÓN}

Sin haber afianzado procesos consistentes de verdad, justicia y reparación, resulta inoportuno pensar en la reconciliación. Si bien circula ampliamente un discurso sobre el perdón, este perdón no apunta al restablecimiento de las relaciones entre conciudadanos ni a la transformación del resentimiento entre víctimas y victimarios. Como señalan Uprimny (2006) y Chaparro (2009), más bien se trata de perdones amnésicos, cuyo propósito es pasar la página para dejar las atrocidades en la impunidad y sepultarlas en el pasado.

Si las víctimas ya pagaron el alto precio de la guerra, no deberían también cargar con el costo de la paz (Mersky, 2007, p. 7). Frente a la entronización del perdón como centro de la reconciliación se han esgrimido varios 
argumentos en contra: 1) pretender el perdón de lo cruel, atroz e imperdonable, puede constituir una nueva forma de agravio para las víctimas ${ }^{13}, 2$ ) el perdón es un asunto privado, una cuestión del fuero interno de las víctimas ${ }^{14}$, mientras que la salida del conflicto es una tarea pública y 3 ) el perdón es una categoría de origen teológico, cuya inclusión no es pertinente para un proceso de reconciliación concebido desde una perspectiva secular y civil.

Si las víctimas deciden otorgar el perdón, se trata de un perdón individual y no de un perdón soberano, en donde el Estado perdona a nombre de toda la sociedad, víctimas incluidas. De ser posible el perdón, este tendría un contenido subjetivo, no político, porque:

...iquién tiene derecho a perdonar actos por los que no hay compensación posible en términos de castigo y reparación?, ¿quién los puede perdonar y con qué criterio? [...]. El exterminio, igual que la masacre o el genocidio,

13 Como lo declara León Valencia, acerca de la posición del victimario "ahora ya sé, o quiero saber, que un hombre que ha sido desterrado de la especie humana, que un hombre librado a la condición de animal, que un hombre al que no se le reconoce razón alguna, no puede buscar la redención ni puede darla. Ahora sé, o quiero saber, que si no hay razones para la guerra, no hay razones para la paz" (Valencia, 2009, p. 218).

14 Además, el perdón es un elemento crucial en la justicia restaurativa, que no necesariamente se debe extrapolar a los procesos transicionales. Según Uribe de Hincapié, "en un país como Colombia donde los marcos culturales de la memoria como diría Halbwachs (2004) facilitarían la adopción de procedimientos que se asemejan mucho a aquellos mediante los cuales los fieles confiesan sus pecados ante un sacerdote para ser perdonados por la infinita misericordia divina, con la confianza en que serán absueltos tantas veces como lo requieran; confesión, perdón y absolución en un país educado en el catolicismo, constituyen una práctica asentada en las mentalidades y en las tradiciones más arraigadas de allí que se pueda esperar un relativo éxito de este argumento, que manejado de manera pragmática, se puede convertir en su contrario: en una vía de escape para que los victimarios evadan la justicia, para que los gobiernos no enfrenten dificultades para las desmovilizaciones y entrega de armas, para que la sociedad se excuse de tener que mirar de frente el horror y hasta para las víctimas, que compelidas por el deber religioso de perdonar sientan que así están ganando el cielo" (2007, p. 33). hacen que toda palabra de perdón sea literalmente imposible (Chaparro \& Galindo, 2009, p. 257).

Incluso es necesario examinar si el lenguaje del perdón, con la pretensión de reafirmar la unidad nacional, no termina generando un efecto contraproducente. Además de admitirse la validez del perdón como proceso social para la reconciliación, sería necesario promover la recuperación de la verdad y la memoria. Sólo desde un olvido activo se podría perdonar aquello comprendido, porque el perdón está ligado a la verdad y el arrepentimiento.

Como se señaló en páginas anteriores, la transición colombiana aún no ha logrado darle un lugar significativo a la verdad. Y lo más grave es que los perpetradores no asumen posturas de culpa y arrepentimiento por los hechos. Si bien en las versiones libres pueden llegar a declarar su autoría material en la comisión de las atrocidades, no asumen ninguna clase de responsabilidad moral ni muestran compasión o respeto por el sufrimiento de sus víctimas. Por el contrario, los perpetradores encarnan actitudes cínicas frente a ellas, y en vez de ofrecerles expresiones de culpa, se muestran triunfalistas y se autoproclaman como los salvadores de la nación; a fin de cuentas consideran que su acción fue indispensable para liberar a Colombia de la violencia guerrillera y detrás de esta actitud mesiánica, aparecen posturas de omnipotencia y arrogancia.

Por otra parte, es necesario revisar el controvertido tema de los perdones recíprocos y su relación con los conflictos simétricos. En esta clase de conflictos no existe una victimización vertical -del Estado hacia la sociedad civil, por ejemplo- sino una victimización 
horizontal, en donde los efectos de la violencia se reparten por igual. El problema es el siguiente: cuando se admite la simetría del conflicto, como lo hace Orozco (2005), esto dificulta en extremo la diferenciación de víctimas y victimarios debido a la alternancia de roles entre ellos, sería necesario hablar de perdones recíprocos.

Por su parte, Uprimny prefiere catalogar el conflicto armado interno en Colombia como un conflicto asimétrico, en donde una sociedad civil inerme y neutral recibe todo el efecto de la victimización. Según el autor:

\begin{abstract}
...en Colombia no es claro que estemos en una violencia horizontal masiva, con formas de victimización recíproca generalizadas. Sin excluir que esa violencia recíproca existe y puede ser importante, no creemos que Colombia esté viviendo una guerra civil con alta movilización ciudadana a favor de los distintos actores en pugna [...] creemos que en nuestro país, la población civil está sufriendo una victimización múltiple, por parte de los diferentes actores armados. En tal contexto no existe ni razón ética ni política para que las víctimas en particular, y la sociedad colombiana en general, deban aceptar los perdones recíprocos que pudieran darse entre las cúpulas de los actores armados (Uprimny, 2004, p. 126).
\end{abstract}

La reconciliación no depende tanto del perdón como de la superación de la polarización, en un contexto donde "cualquier disenso supone la estigmatización, la exclusión, y probablemente una nueva victimización de las víctimas que no se integren al modelo" (Chaparro \& Galindo, 2009, p. 288). En el mismo horizonte, las experiencias transicionales exitosas enseñan que en un escenario postconflicto todos los actores enfrentados en el pasado, deben contar con un lugar en la nueva sociedad. Este es el máximo reto de la reconciliación porque los antiguos combatientes y perpetradores de todos los bandos deben incluirse en la nueva apuesta de sociedad. Cuando algún sector queda excluido del nuevo pacto, no tiene un incentivo real para salir del conflicto y la transición sería sólo un espejismo. Según León Valencia:

...la reincorporación a la vida civil en el marco del proyecto de reconciliación implica que todas las energías del Estado, de la empresa privada y de la comunidad internacional se concentran en superar las causas que dieron origen al conflicto, en la reconstrucción del país y en establecer incentivos económicos, sociales y políticos para quienes regresan a la vida civil. También y principalmente, en la ardua tarea de reparar a las víctimas, empezando por reconocer la responsabilidad del Estado en la crisis humanitaria (2009, p. 218).

En torno al concepto de paz aparece un nuevo debate, porque no es claro qué queremos como sociedad cuando decimos que la buscamos. Una primera acepción podría ser la paz minimalista, limitada al silencio de las armas. No obstante, en este peculiar escenario de postconflicto armado, no todos los grupos participaron, quienes participaron lo hicieron a medias y dentro de ellos hay quienes siguen delinquiendo desde las bandas emergentes. La aplicación de medidas de justicia transicional a una sociedad no transicional no ha tenido como efecto la consecución de la paz, ni siquiera en su acepción más minimalista y austera. Por supuesto, tampoco se ha alcanzado una concepción maximalista de la paz, capaz de comprender y transformar las causas estructurales que originaron el conflicto. Según este enfoque, el proceso de reconciliación sólo es viable con altísimos estándares de justicia, porque el derecho 
de las víctimas no contradice el derecho a la paz del resto de la sociedad. Estamos de acuerdo con Uribe de Hincapié, cuando se refiere a una idea retórica de la paz:

..."la paz" en esta estrategia discursiva es una palabra vacía pero con una alta eficacia simbólica en un país como Colombia que la quiere, la espera y la demanda; se trata pues de la reproducción de un cierto presentismo; de la repetición de tradiciones históricas bajo contextos distintos; de estrategias pragmáticas y puntuales para resolver las tensiones de la coyuntura que gracias a la magia de las palabras se hacen pasar como soluciones definitivas. La paz sustitutiva de la justicia anula ese punto difícil de equilibrio entre ambos términos sobre los cuales se sustentan los principios tutelares de la justicia transicional, la niega, la desvirtúa pero se recubre con su discurso para darle al menos un barniz de legitimidad al proceso frente a las evidencias de arrinconamiento de las víctimas, el clamor contra la impunidad y las exigencias nacionales e internacionales de alguna forma de justicia (2007, p. 30).

\section{Colombia, ¿UNA SOCIEDAd POSTCONFLICTO?}

En este punto de la argumentación es posible establecer una conclusión parcial, Colombia no es una sociedad postconflicto y la aplicación de las estrategias de la justicia transicional se dio fuera de contexto. Si ocurrió una desmovilización de los actores armados, ésta tuvo un carácter parcial, porque no participaron en ella todos los miembros de las AUC; además, las FARC estuvieron completamente marginadas del proceso. En particular, este grupo guerrillero desaprovechó el escenario de negociación ofrecido por el gobierno Pastrana. Dado que la salida negociada del conflicto no fue considerada como una opción viable por parte de la ad- ministración Uribe, la guerrilla persistió en la lucha armada y no se acogió a los beneficios de la Ley de Justicia y Paz.

La situación de este grupo guerrillero es compleja. Si bien se trata de una organización ilegal diezmada en hombres y derrotada moralmente, desde el punto de vista militar conserva su capacidad de agresión. Como resulta evidente, con este grupo armado no se dio ni una derrota militar ni una salida negociada al conflicto. Con la negación del estatuto beligerante de la organización y del carácter de delincuencia política de su accionar, se afirmó su talante terrorista. Entonces, ¿qué Estado decente podría negociar con bandoleros y terroristas? Este análisis le abrió paso a una política de mano dura y de exterminio militar desde la lógica del enemigo, en respuesta a la amenaza terrorista. No obstante, las experiencias internacionales muestran que aún con la derrota total de la insurgencia por parte del Estado, la ausencia de una salida política tiene como efecto el resurgimiento de nuevos enfrentamientos en el marco de un frágil postconflicto.

Según esto, si los actores del conflicto armado permanecen activos, no es pertinente hablar de una situación postconflicto. La guerrilla no se desmovilizó y las AUC lo hicieron parcialmente. Además, un porcentaje importante de los paramilitares desmovilizados se reconfiguró en nuevas organizaciones armadas, propiciando el surgimiento de las bandas emergentes. Para analistas como León Valencia (2009), esta situación produjo un cambio nominal, una sustitución de la razón social sin una intervención real de las causas estructurales del conflicto. La idea de postconflicto armado es una contradicción en los términos. Sin duda estamos en 
un país esquizofrénico, donde se vive una situación de postconflicto con la extrema derecha desarmada y de conflicto con la extrema izquierda armada (Santos, 2009, XI).

Destacados analistas consideran el caso colombiano como una experiencia ejemplar de justicia transicional para otros países, porque encuentran en la Ley 975 de 2005 uno de los marcos más elaborados y exigentes. En esta línea argumenta Alfredo Rangel (2009) ${ }^{15}$, quien considera que ningún proceso en el mundo ha alcanzado tanta verdad, justicia y reparación. En un tono similar también se orienta el análisis de Eduardo Pizarro:

\begin{abstract}
Se trata de una ley sin antecedentes en Colombia, y, probablemente, en el mundo. Sin antecedentes en Colombia, pues mediante este novedoso modelo de justicia nació en la conciencia nacional la figura de la víctima como portadora de derechos a la verdad, a la justicia y a la reparación [...] sin antecedentes en el mundo, pues todas las experiencias de justicia transicional o restaurativa se han desarrollado, con múltiples altibajos, ya sea en contextos de posdictadura (Chile y Argentina), en experiencias de postconflicto (Guatemala y El Salvador), o en el caso de Sudáfrica, en el contexto del posapartheid. En Colombia estamos intentando desarrollar una compleja modalidad de justicia transicional en un país en el cual persiste el conflicto interno (Pizarro, 2009, p. 5).
\end{abstract}

Esto es lo que Uprimny llama justicia transicional sin transición. También se advierte un tono optimista en torno a la situación postconflicto. A juicio de Pizarro:

...ya en Colombia se está hablando y, con argumentos sólidos, de los gérmenes de un posconflicto. Estos gérmenes

15 Al respecto v. el prólogo escrito por el autor, en el texto Justicia y paz ¿Cuál es el precio que debemos pagar? Bogotá: Intermedio Editores. se deben, en gran medida, a la aplicación de un modelo de justicia transicional que facilitó la desmovilización de las Autodefensas Unidas de Colombia (Pizarro, 2009, p. 37).

Esta apreciación se basa en dos supuestos discutibles. En primer lugar, asume que la implementación temprana y descontextualizada de las políticas y estrategias transicionales tendrán como efecto una situación postconflicto. La argumentación expuesta en esta investigación defiende la imposibilidad de incorporar el paradigma de la justicia transicional en medio del conflicto armado y de hablar de un postconflicto armado. En segunda instancia, la posición de Pizarro da por hecho la desmovilización de las AUC y la considera un elemento suficiente para diseñar escenarios de paz. Si bien cada experiencia transicional es única en su género y no puede extrapolarse sin más a otros contextos, también es necesario reconocer la existencia de un capital de saber acumulado que los nuevos procesos transicionales en el mundo no deberían desconocer.

Las particularidades del conflicto armado colombiano, largo, fragmentado en el tiempo, diferenciado en el espacio y con la presencia simultánea de varios operadores de violencia, hacen más complejo y abigarrado el esclarecimiento de la verdad, la aplicación de la justicia y la orientación de las reparaciones. Es necesario entender qué no se han reconstruido las causas del conflicto ni se ha dado una solución efectiva frente a ellas. Se trata de un conflicto armado interno con una duración de casi 60 años, con diferentes etapas, objetivos, actores y motivaciones. Además, la fusión del narcotráfico con las actividades terroristas de los diferentes grupos alzados en armas se ha convertido en una fuente de exacerbación del conflicto 
en los últimos 20 años, cuya amenaza no se extingue con la promulgación formal de la Ley de Justicia y Paz.

Por ello, emprender iniciativas postconflicto en medio del conflicto no puede reivindicarse sin más, como una manifestación idiosincrática ni como una peculiar expresión de nuestra cultura política. Para los especialistas la temprana aplicación de la justicia transicional significó una negación a la evidente situación de conflicto armado aún persistente en Colombia; para otros, constituye una gradual legalización y politización de las AUC, aprovechando los marcos jurídicos empleados en las transiciones llevadas a cabo en otros países.

Los marcos teóricos y las experiencias internacionales son referentes que permiten tomar distancia y evaluar la situación interna sin apasionamientos. Colombia no es una sociedad postconflicto ni en sentido estricto, a ella le competen los mecanismos de la justicia transicional. Una situación postconflicto presupone el desarrollo de diálogos de paz, la desmovilización de todos los actores armados, la creación de comisiones de verdad y la reconciliación entre los sectores y grupos antes enfrentados; y sobre todo, implica la creación de un nuevo pacto social incluyente, cuyo objetivo sea lograr la reconstrucción social, política y económica del país.

Finalmente, existen otras consideraciones distintas a las políticas y militares, que impiden hablar de postconflicto. En primer lugar, hay razones económicas, porque un escenario postconflicto viable implica una transformación estructural en el modelo económico del país, que produzca un cambio sustancial en la justicia distributiva y permita avanzar hacia metas de justicia social. En segundo lugar, se hace necesario un nuevo diseño institucional orientado a generar los cambios estructurales requeridos para garantizar el éxito de la transición.

\section{Conclusiones}

En las transiciones exitosas es posible observar una voluntad política clara por conocer la verdad y generar condiciones para la reconciliación. Por ejemplo, en Sudáfrica el gobierno de Frederik de Klerk puso fin al régimen de exclusión racial, al derogar las leyes segregacionistas y emprender una política encaminada a defender la igualdad racial y proteger los derechos humanos. Con la elección de Raúl Alfonsín como presidente, se puso en marcha la transición argentina y fue posible ponerle fin a los excesos de la dictadura cívico-militar, conocida con el nombre de proceso de Reorganización Nacional. En el gobierno de Alfonsín se realizó el juicio a las juntas militares y se inició al proceso de esclarecimiento de la verdad histórica. En los dos casos mencionados se destacó que la transición perdió su carácter político y quedó en manos de la justicia.

En la mayoría de las experiencias internacionales, las leyes de purga también fueron muy importantes. Lo principal para garantizar el verdadero tránsito de un régimen a otro fue sacar del gobierno y de los empleos públicos a las personas que participaron directa o indirectamente en las violaciones de los derechos humanos. De no ser así, los ciudadanos vivirían con la sospecha de una identidad política presente, emergida de las concepciones ideológicas que hicieron posibles los abusos.

En el caso colombiano, la transición incipiente nunca reconoció el vínculo de los paramilitares con los agentes del Estado, 
ni sus nexos con dirigentes políticos de la coalición de gobierno. Al inicio del proceso, tampoco se aceptó la participación de los paramilitares en actividades de narcotráfico, pues se presentó esta organización como un proyecto contrainsurgente de finalidades exclusivamente políticas. No obstante, para De Greiff "la reforma institucional, con los procesos de descalificación como punto de partida, está guiada por el ideal de garantizar las condiciones bajo las cuales los ciudadanos pueden relacionarse los unos con los otros y con las autoridades como iguales" (2009, p. 48).

Como lo señalan Uprimny (2009) y Uribe de Hincapié (2007), en Colombia se han combinado dos paradigmas de justicia transicional, teóricamente centrados en la retribución y la restauración. En lugar de tomar los mejores recursos de estos modelos, no se potenciaron sus complementariedades y recurrió a lo peor de ambos. En realidad no se trató de una verdadera articulación, sino de una yuxtaposición ecléctica, pues los fines de la política se superponen a la normatividad jurídica. El proceso transicional tuvo un tono más bien pragmático, marcado por la manipulación y el decisionismo. Este privilegio de la discrecionalidad estatal frente a la ley encarna la máxima de Schmitt, en donde el Estado funda la ley y no al revés. Es así como ha emergido:

...la paz como sustitución de la justicia; la verdad como objeto intercambiable y la ceremonia del perdón, que constituyen los desvíos, los quiebres y las estrategias mediante las cuales se ha venido interpretando en Colombia el paradigma de la justicia transicional; si bien es cierto que no existe un modelo único y válido para todos los países, que las realidades históricas y políticas de las naciones le imponen su propio sello a los procesos transicionales y que los pueblos están obligados a buscar los caminos más apropiados para llevarla a cabo, aprendiendo al mismo tiempo de las experiencias de otros lugares, lo que no resulta apropiado ni ético, es torcerle el cuello al paradigma, usarlo como retórica vacua para encubrir otras intenciones menos presentables o para ocultar las debilidades históricas del Estado colonizado por los operadores de violencia (Uribe de Hincapié, 2007, p. 35).

El modelo transicional colombiano ha tenido como prioridad garantizar condiciones para la desmovilización de los victimarios y no para la reparación de las víctimas. Por esta razón, en el futuro se deben privilegiar los derechos de las víctimas antes que el interés de los perpetradores por acceder a determinados beneficios judiciales. Uno de los grandes problemas en la implementación de la Ley de Justicia y Paz ha sido su visión de corto plazo para atender las causas y efectos del conflicto. Pero una transición consistente no puede limitarse a apagar incendios, $\mathrm{ni}$ como dice Pizarro (2009), a reparar el bote en alta mar. Una iniciativa de mediano y largo plazo para propiciar una transición política real, debe enfocarse en ampliar las posibilidades de participación y expresión de la sociedad civil. Así, la sociedad civil debe entenderse como un actor relevante para configurar los escenarios futuros y sobre todo, para recuperar la memoria sobre el conflicto y sus atrocidades.

Como lo señalan Uprimny (2009) y Valencia (2009), en medio de un proceso tan criticado y cuestionable, es preciso rescatar algunos elementos valiosos. Entre ellos, la Ley de Justicia y Paz abre una ventana de oportunidad para iniciar un proceso paulatino en donde las reivindicaciones de las víctimas puedan posicionarse en la agenda pública. 
Asimismo, es importante el papel de la comunidad internacional, de las asociaciones de víctimas y de las investigaciones académicas para promover procesos de cambio y participación en medio de una transición que aunque anómala ya no puede reversarse. El asunto entonces, como dice el adagio popular, es hacer de la necesidad virtud, para potencializar las oportunidades ofrecidas por la Ley de Justicia y Paz y encontrar un lugar preponderante para las víctimas en el marco de un nuevo pacto social.

La sociedad civil debe superar sus actitudes de indiferencia frente al dolor de las víctimas y ante los excesos de un conflicto que ha pasado por alto las reglas de la guerra, violando un mínimo respeto a la dignidad humana. Los ciudadanos no pueden seguir impávidos ante los delitos de lesa humanidad, ni ser tolerantes con las violaciones de los derechos humanos. Tampoco pueden repudiar los actos de unos grupos ilegales cuando se guarda un silencio cómplice ante los cometidos por los grupos opuestos, como si no existiera un canon objetivo para clasificar penalmente estos delitos y haciendo depender su valoración en el grupo alzado en armas que actuó como perpetrador.

Este balance agridulce sobre el postconflicto y los procesos transicionales en Colombia se resume en el siguiente análisis de León Valencia. El autor insiste en el carácter confuso de la situación por la que atraviesa el país:

\footnotetext{
He dicho que la Ley 975 de 2005 fracasó en sus propósitos esenciales, pero con ella se ha iniciado la época de la justicia transicional en Colombia. He planteado que no estamos aún en la transición de la guerra a la paz, pero hay elementos de reconciliación en lo que se está haciendo en reinserción, verdad y reparación. He dejado ver que en esta trama
}

hay grupos y personas que no están aún en un proyecto de justicia transicional y paz, y otros que están caminando en esa dirección. Entre los primeros, están tanto los actores armados ilegales, como el presidente Uribe y su Alto Comisionado para la Paz, Luis Carlos Restrepo; entre los segundos se encuentran la Corte Constitucional, la Corte Suprema de Justicia, la Fiscalía General de la Nación y otras instituciones y funcionarios del Estado, importantes sectores de la comunidad internacional $\mathrm{y}$, de modo especial, las víctimas y sus organizaciones. Todo ello es tan difícil de entender y tan contradictorio como aquello de que estamos en un conflicto armado, negando el conflicto, negociando el conflicto y con elementos claros de posconflicto. Pero esa es nuestra realidad apasionante y dolorosa (Valencia, 2009, p. 274).

En conclusión, el estudio comparativo de las experiencias internacionales aporta valiosas lecciones. Por ejemplo, que la justicia transicional no debe pensarse sin la preparación de un escenario postconflicto. En otro caso, se daría un limitado cumplimiento de lo penal, una escasa reparación y ninguna transformación estructural de las causas del conflicto.

\section{RECOMENDACIONES NORMATIVAS PARA UN POSIBLE ESCENARIO POSTCONFLICTO}

A continuación se presenta una serie de recomendaciones para continuar en el proceso transicional emprendido por la Ley de Justicia y Paz. Estas recomendaciones parten de un enfoque normativo cuya aspiración es superar la descripción de los hechos empíricos (el fenómeno o el ser), para darle lugar al deber ser. Desde esta perspectiva, la tarea de la filosofía no es, como pretendía Wittgenstein, dejar las cosas como están, 
porque resulta necesario y urgente aportar marcos teóricos para la apropiación reflexiva de los hechos y contribuir a su intervención y transformación. En este sentido, no hablamos del postconflicto como un hecho fáctico sino como un escenario posible que es necesario empezar a construir. Por ello,
...la imaginación política nos permite construir mundos posibles para orien- tar la acción política y complementar los análisis políticos sobre el poder mi- litar y territorial [...]. Necesitamos nue- vas categorías filosóficas que junto con la científicas nos permitan mejorarnos a nosotros mismos y reorientar bajo pa- rámetros de virtud y justicia el destino de nuestras sociedades (Arango, 2007, pp. 13-14).

En este contexto se proponen unos mínimos normativos para regular la aplicación del paradigma de la justicia transicional, orientados hacia la búsqueda de lo justo, lo legal, lo bueno y lo preferible. Estos mínimos no apelan a un fundamento a priori o trascendental, porque parten del análisis de los fenómenos concretos. Son plausibles porque pueden responder pertinentemente a las circunstancias actuales, de manera que orienten acciones y decisiones futuras. Los mínimos normativos propuestos son los siguientes:

a) Reconocer el carácter holístico e integral de las medidas de justicia transicional. Expertos como De Greiff (2009) y Mersky (2007), explican que estas medidas deben implementarse desde un enfoque integrador y sistémico, porque sólo así es posible superar la improvisación, la aleatoriedad y el azar, propia de los enfoques inmediatistas. En los procesos transicionales todos los elementos están interrelacionados y ello implica un cambio de concepción epistemológico en el modo de entender y asumir la transición. En consecuencia, no es adecuado aplicar medidas selectivas y aisladas, desde que se promuevan intervenciones parciales y reduccionistas, porque estarían desprovistas de un verdadero efecto transformador.

b) Buscar el equilibrio entre las dinámicas del contexto y los estándares internacionales de la justicia transicional. En una importante medida la justicia es una construcción histórica que recoge las tradiciones y las interacciones culturales de un contexto determinado. Sin embargo, la invocación de una actitud comunitarista, opuesta a la adopción acrítica de los referentes de la justicia global y de las experiencias transicionales llevadas a cabo en otros países, no significa dar vía libre al pragmatismo o en el oportunismo. Aunque los diseños institucionales deben responder a la dinámica particular del conflicto, es imposible y dadas nuestras condiciones de impunidad, también indeseable, que se busquen espacios de maniobra para evadir el Derecho Internacional Humanitario, en aras el ejercicio de la soberanía ${ }^{16}$. La afirmación de la soberanía no está por encima del derecho internacional y por ello es necesario superar la doctrina del interés nacional y la concepción moderna de la soberanía absoluta del Estado.

16 Frente a las restricciones del derecho internacional en las posibilidades de maniobra en la negociación para la transición, se destacan las posturas de Pizarro Leongómez (2009) y Orozco Abad (2005). Para el primero, países como Chile, Argentina y Suráfrica tuvieron procesos transicionales exitosos porque no estaban restringidos por los imperativos del derecho internacional. Según esto, los países que como Colombia emprenden su transición después de la creación de la Corte Penal Internacional no tienen las posibilidades de indulto y amnistía, lo cual dificulta los procesos de negociación. Por ello, el equilibrio entre la justicia y la paz, según sus palabras, resulta la cuadratura del círculo. Por su parte, Orozco Abad señala que sería necesario encontrar posibilidades de maniobra frente al marco normativo hegemónico impuesto por una pretendida consciencia humanitaria. 
La configuración de un nuevo orden internacional exige superar la división entre el derecho, la moral y el sometimiento del poder político al derecho, porque el problema de la paz además de político es jurídico (Kelsen, 2007).

c) Buscar la paz sin sacrificar la justicia. La paz y la justicia no resultan valores antagónicos cuando los diferentes sectores implicados en el conflicto o afectados por él están dispuestos a asumir un razonable punto medio. El maximalismo de las víctimas reclamando justicia o el minimalismo de los avatares políticos, sometidos a la negociación y a los acuerdos permanentes, deben encontrar un punto equidistante entre la paz y la justicia. La paz y la reconciliación no tienen por qué identificarse con la impunidad o con el desconocimiento de las víctimas. Tampoco es correcto perpetuar la polarización, el resentimiento y la sed de venganza en nombre de la justicia. En un proyecto de reconciliación todos los actores deben sacrificar algo, para que la sociedad como conjunto pueda ganar.

d) Recuperar la relación entre la moral y el derecho, desde un punto de vista normativo. La actitud realista le da más peso a la política que al derecho, a la vez que excluye la moralidad. Por esta razón los procesos transicionales no deberían estar dominados por el realismo, sino buscar su regulación en unos mínimos normativos sin recurrir a fundamentos teológicos, aprioristas o trascendentales. Recuperar el vínculo entre el derecho y la moral, desde un enfoque secular, puede constituir una alternativa al pragmatismo y decisionismo im- perante. No toda ley es justa y el derecho debería fundarse en el deber ser de las leyes. En este contexto es necesario preguntar, ¿cuál es la norma y el valor supremo en que se funda la Ley de Justicia y Paz? Esta norma no debería depender sólo de la voluntad positiva del legislador, ni identificar la justicia de la ley con el mandato, porque no todo lo que está mandado es justo. Estamos de acuerdo con Dworkin en la siguiente premisa: la legitimidad del derecho proviene de su justificación, cuya validez no puede sustentarse en un puro convencionalismo pragmático. El derecho no es un ámbito arbitrario y por ello es necesario abrirle espacio a la discusión ciudadana frente a la racionalidad y corrección moral de la ley (Dworkin, 1992). Esto permitiría crear escenarios para la oposición y el disenso en una sociedad verdaderamente plural, donde el opositor no se identifique con el enemigo o el terrorista.

e) Abrir espacios para la justicia social en el marco de los procesos transicionales. Las discusiones y dilemas en torno a la justicia no deben limitarse a los modos de integración entre la justicia retributiva y la justicia restaurativa, ni agotarse en la discusión acerca de qué grado de punición es deseable. Estas nociones de justicia deben ser ampliadas y complementadas con una perspectiva de justicia distributiva que permita pensar en términos de equidad, inclusión y bienestar. Una transición sostenible debe pensar en la restitución de los derechos de las víctimas, pero también en la prevención de nuevas victimizaciones y exclusiones. La reconstrucción postconflicto debe asumir reformas 
sociales y económicas de fondo, más allá de las compensaciones y paliativos. El reto es enfocarse en los problemas de marginalidad, pobreza y exclusión. En conclusión, es necesario complementar la orientación penal de la justicia con un enfoque más social.

f) Generar las condiciones para un nuevo contrato social. Esto implica, desde los aportes de Kaldor (2005), la promoción de un nuevo rol de la sociedad civil en un marco transnacional y cosmopolita. El propósito de un nuevo contrato social no es entregar la libertad o el ejercicio de la fuerza a un tercero que se erige como soberano; por el contrario, el objetivo es fortalecer ciudadanías activas, críticas y participativas a partir de las cuales pueda ser posible construir un modelo de país más incluyente, de modo que el temor y la violencia desaparezcan de la vida cotidiana. Deberíamos pensar en un nuevo pacto social entre los ciudadanos, para decidir en qué tipo de sociedad postconflicto queremos vivir. No se requiere del caudillo propuesto por Schmitt, como un representante de la voluntad general y responsable de consumar su decisión fundamental. Este pacto no debería acoger únicamente las expectativas de las víctimas, sino del conjunto de la sociedad.

g) Evitar el extremismo, el fundamentalismo y la polarización. En un ambiente de ánimos caldeados y culturalmente, propenso a la solución violenta de los conflictos, es necesario promover la mesura, el equilibrio y el respeto por todos los interlocutores. Lo importante es generar un ambiente proclive al diálogo racional, superando las actitudes reactivas que ven en el disenso la señal indefectible del enemigo.

h) Superar la lógica del enemigo. En un mundo globalizado la afirmación de la soberanía estatal en función de la identificación del enemigo interno es un concepto revaluado. Por ello, es necesario avanzar hacia una actitud pluralista porque el opositor no debe ser estigmatizado como guerrillero o terrorista. Quien no se adhiere al discurso oficialista no necesariamente es el enemigo o el brazo político de los grupos armados. En un mundo hobbesiano el soberano puede decretar cuáles son las actitudes políticas correctas, cómo deben hablar los súbditos y en qué doctrinas pueden creer sin incurrir en la sedición o la herejía. Pero en una sociedad abierta y deliberante está de más el fiat soberano que pretende establecer el significado y la verdad en el discurso público.

i) Recuperar el papel de las emociones morales en la comprensión y superación del conflicto. Según Arango,

...un estudio integral de la ley, su puesta en práctica y sus previsibles efectos situaría a las emociones morales, como el resentimiento, la indignación, la vergüenza, la culpa y la compasión en el centro de análisis constitucional. Ello porque tales emociones son funcionales al llamado nivel de tolerancia moral del derecho, criterio de validez extraído de la experiencia histórica y cultural de aumento en la sensibilidad humana frente a los actos atroces. De este aumento de la sensibilidad y consecuente reducción del nivel de tolerancia frente a actos extremadamente injustos, podemos esperar una mayor comprensión por la situación de las víctimas, pero una mejor comprensión de la bancarrota moral de nuestra sociedad (2007, p. 113). 


\section{REFERENCIAS}

Arango, R. (2007). Derechos humanos como límite de la democracia. Análisis de la Ley de Justicia y Paz. Bogotá: Universidad de los Andes - Grupo Editorial Norma.

Beristain, C. (2007). Reconciliación luego de conflictos violentos: un marco teórico. En: Verdad, justicia y reparación. San José de Costa Rica: Instituto Interamericano de DD.HH.

Cárdenas, M. (2003). La construcción del posconflicto en Colombia. Enfoque desde la pluralidad. Bogotá: FESCOL - CEREC.

Castellanos, E. (2008). Justicia transicional en Colombia. Formulación de propuestas desde un análisis comparado. Bogotá: Universidad Nacional de Colombia.

Cepeda, I. (2005). La segregación de las víctimas de la violencia política. En: Rettberg, A. (Coord.). Entre el perdón y el paredón. Preguntas y dilemas de la justicia transicional. Bogotá: Universidad de los Andes. Programa de Investigación sobre Construcción de Paz. Departamento de Ciencia Política. Facultad de Ciencias Sociales.

Chaparro, A. (2009). Estado y justicia transicional. El caso de las AUC. En: Chaparro, A. \& Galindo, C. Génesis y transformaciones del Estado nación en Colombia. Bogotá: Universidad del Rosario.

Cruz, C. \& Ortega, A. (2010). Pensando el futuro: consideraciones sobre FFMM y postconflicto en Colombia. En: Colombia: Escenarios posibles de guerra o paz. Bogotá: Universidad Nacional de Colombia.

De Gamboa, C. (2006). Teoría y praxis de la justicia transicional. Bogotá: Universidad del Rosario.
De Greiff, P. (2009). Una concepción normativa de la justicia transicional. En: Rangel, A. (Ed.). Justicia y paz ¿cuál es el precio que debemos pagar? Bogotá: Intermedio Editores.

Dworkin, R. (1992). El imperio de la justicia: de la teoría general del derecho, de las decisiones e interpretaciones de los jueces y de la integridad politica y legal como clave de la teoría y práctica. Barcelona: Gedisa.

Elster, J. (2006). Rendición de cuentas. La justicia transicional en perspectiva histórica. Buenos Aires: Katz Editores.

Giraldo, J. (2004). Búsqueda de verdad y justicia. Seis experiencias en posconflicto. Bogotá: CINEP.

Guerra, M. \& Plata, J. (2005). Estado de la investigación sobre conflicto, postconflicto, reconciliación y el papel de la sociedad civil en Colombia. Revista de Estudios Sociales, (21), Universidad de los Andes.

Kaldor, M. (2001). Las nuevas guerras: la violencia organizada en la era global. Barcelona: Tusquets Editores.

Kaldor, M. (2003). La sociedad civil global: una respuesta a la guerra. Barcelona: Tusquets Editores.

Kelsen, H. (2008). La paz por medio del derecho. Introducción de Massimo La torre y Cristina García Pascual. Madrid: Editorial Trotta.

Lefranc, S. (2007). La eficacia de la justicia de transición. En: El legado de la verdad: impacto de la justicia transicional en la construcción de la democracia en América Latina. Lecciones para Colombia. Bogotá: Centro Internacional de Justicia Transicional. 
López, C. (2007). La ruta de la expansión paramilitar y la transformación de la política en Antioquia. En: Achila, L. (Ed.). Parapolítica. La ruta de la expansión militar y los acuerdos políticos. Bogotá: Corporación Nuevo Arco Iris - Intermedio Editores.

Mersky, M. (2007). El legado de la verdad: algunas reflexiones. En: El legado de la verdad: impacto de la justicia transicional en la construcción de la democracia en América Latina. Lecciones para Colombia. Bogotá: Centro Internacional de Justicia Transicional.

ONU (2007). Objetivos de desarrollo del milenio. Nueva York.

Orozco, I. (2005). Reflexiones impertinentes: sobre la memoria y el olvido, sobre el castigo y la clemencia. En: Rettberg, A. Entre el perdón y el paredón. Preguntas y dilemas de la justicia transicional. Bogotá: Universidad de los Andes. Programa de Investigación sobre Construcción de Paz. Departamento de Ciencia Política. Facultad de Ciencias Sociales.

Pizarro, E. (2009). Reparar el bote en alta mar. En: Pizarro, E. \& Valencia, L. Ley de justicia y paz. Bogotá: Grupo Editorial Norma - Semana.

Rettberg, A. (Coord.) (2005). Entre el perdón y el paredón. Preguntas y dilemas de la justicia transicional. Bogotá: Universidad de los Andes. Programa de Investigación sobre Construcción de Paz. Departamento de Ciencia Política. Facultad de Ciencias Sociales.

Rettberg, A. (Coord.) (2002). Preparar el futuro: conflicto y postconflicto en Colombia. Bogotá: Universidad de los Andes Fundación Ideas para la Paz.
Schmitt, C. (1992). El concepto de lo político. Madrid: Alianza Universidad.

Uprimny, et ál. (2006). ¿Justicia transicional sin transición? Verdad, justicia y reparación para Colombia. Bogotá: Centro de Estudios de Derecho, Justicia y Sociedad.

Uprimny, R. \& Lasso, L. M. (s.f.) Verdad, reparación y justicia para Colombia. En: Conflicto y seguridad democrática en Colombia. Bogotá: Norma.

Uprimny, R. \& Saffon, M. (2005). Justicia transicional y justicia restaurativa. Tensiones y complementariedades. En: Rettberg, A. (Coord.). Entre el perdón y el paredón. Preguntas y dilemas de la justicia transicional. Bogotá: Universidad de los Andes. Programa de Investigación sobre Construcción de Paz. Departamento de Ciencia Política. Facultad de Ciencias Sociales.

Uprimny, R. \& Saffón, M. (2009). Usos y abusos de la justicia transicional en Colombia. Rangel, A. (Ed.). En: Justicia y paz, ¿cuál es el precio que debemos pagar? Bogotá: Intermedio Editores.

Uribe de Hincapié, M. (2007). El legado de la verdad: una lección para Colombia. En: El legado de la verdad: Impacto de la Justicia Transicional en la construcción de la democracia en América Latina. Lecciones para Colombia. Bogotá: Centro Internacional de Justicia Transicional.

Valencia, L. (2009). Ni justicia ni paz. En: Pizarro, E. \& Valencia, L. Ley de Justicia y Paz. Bogotá: Grupo Editorial Norma - Semana.

Walzer, M. (2004). Reflexiones sobre la guerra. Barcelona: Ediciones Paidós. 